\title{
Combination of Early EEG, Brain CT, and Ammonia Level Is Useful to Predict Neurologic Outcome in Children Resuscitated From Cardiac Arrest
}

\author{
Donghwa Yang, Eell Ryoo and Hyo Jeong Kim*
}

Department of Pediatrics, Gachon University Gil Medical Center, Gachon University College of Medicine, Incheon, South Korea

OPEN ACCESS

Edited by:

Utpal S. Bhalala,

Baylor College of Medicine,

United States

Reviewed by:

Arun Bansal,

Post Graduate Institute of Medical

Education and Research

(PGIMER), India

Asha N. Shenoi,

University of Kentucky, United States

Vijay Srinivasan

Children's Hospital of Philadelphia

United States

*Correspondence:

Hyo Jeong Kim

greatelena@naver.com

Specialty section:

This article was submitted to

Pediatric Critical Care,

a section of the journal

Frontiers in Pediatrics

Received: 22 February 2019

Accepted: 20 May 2019

Published: 04 June 2019

Citation:

Yang D, Ryoo E and Kim HJ (2019)

Combination of Early EEG, Brain CT,

and Ammonia Level Is Useful to

Predict Neurologic Outcome in

Children Resuscitated From Cardiac

Arrest. Front. Pediatr. 7:223.

doi: 10.3389/fped.2019.00223
Purpose: Predicting neurologic prognosis in pediatric patients recovered after cardiac arrest is more difficult than in adults. This study hypothesized that a combination model of early electroencephalography, brain computed tomography (CT), and laboratory findings improve prediction performance of neurologic outcome in pediatric patients after cardiac arrest.

Methods: We retrospectively analyzed the medical records of pediatric patients resuscitated after non-traumatic cardiac arrest. Clinical features, electroencephalography, gray matter to white matter attenuation ratio on brain CT, and laboratory findings were analyzed. The primary outcome was neurologic prognosis based on the Pediatric Cerebral Performance Category score.

Results: Of 21 patients, seven (33.3\%) were classified as a good neurologic outcome group and 14 (66.7\%) were classified as a poor neurologic outcome group. The good outcome group was associated with a slow and disorganized electroencephalographic background pattern $(P=0.006)$, reactivity $(P=0.006)$, and electrographic seizures $(P=0.03)$. The frequency of a suppressed electroencephalographic background pattern was significantly higher in the poor outcome group $(P=0.006)$. The poor outcome group was also associated with a low level of gray matter to white matter attenuation ratio $(P=0.03)$ and hyperammonemia $(P=0.003)$. The area under curve of the combined model, consisting of electroencephalographic background, gray matter to white matter attenuation ratio, and ammonia was the highest at $0.959(0.772-0.999)$ with a specificity of $100 \%$.

Conclusion: Unfavorable electroencephalographic background, low gray matter to white matter attenuation ratio on brain $\mathrm{CT}$, and hyperammonemia are associated with poor neurologic outcome in children after cardiac arrest.

Keywords: cardiac arrest, pediatric, neurologic outcome, electroencephalography, gray matter to white matter attenuation ratio, ammonia 


\section{INTRODUCTION}

The annual incidence rate of out of hospital cardiac arrest worldwide varies from 2.6 to 19.7 children per 100,000 $(1,2)$ and the Korean annual incidence rate is 4.2 children per 100,000 (3). Approximately $47-69 \%$ of the patients resuscitated from cardiac arrest remain comatose and do not regain consciousness $(4,5)$. So, predicting the prognosis in children who suffer cardiac arrest is difficult. In adults, an unfavorable electroencephalography (EEG) pattern such as burst-suppression at $24 \mathrm{~h}$ after return of spontaneous circulation (ROSC), no light reflex at $48 \mathrm{~h}$, and the absence of somatosensory evoked potential at $72 \mathrm{~h}$ are predictive of a poor prognosis (6). In studies on pediatric patients, neurologic outcome is good if the early EEG background is normal or if only slowing EEG background is present (7). Structural changes on brain computed tomography (CT) are known to be associated with a poor neurologic prognosis (8). Hyperammonemia is also known as one of signs of poor neurologic outcome (9).

However, the criteria for prediction of prognosis in pediatric patients with cardiac arrest are not clear. The purpose of this study is to investigate the usefulness of early EEG, brain $\mathrm{CT}$ and laboratory findings in predicting neurological outcomes in pediatric ROSC patients after non-traumatic cardiac arrest. In addition, we investigated the neurological prognostic performance of combined models of single variables.

\section{MATERIALS AND METHODS}

\section{Subjects and Study Design}

We retrospectively analyzed the medical records of pediatric patients resuscitated after non-traumatic cardiac arrest at the Gachon University Gil Medical Center from January 2006 to December 2017. Patients between 1 month and 18 years of age were included. Cardiopulmonary resuscitation (CPR) was performed according to the Pediatric Advanced Life Support guidelines at that time during the course of the study (10-12). Patients who were dead on arrival, patients who did not have a CT scan within $24 \mathrm{~h}$, patients who did not undergo EEG within $72 \mathrm{~h}$, and patients who went to other hospitals during treatment were excluded from the study.

\section{Data Collection and Analysis}

We reviewed each patient's medical records retrospectively and collected data on age, sex, arrest etiology, presence of underlying disease, EEG, drugs used during EEG, brain CT imaging, and laboratory findings. EEGs were performed according to international standard 10-20 system for $30 \mathrm{~min}$ as early as possible after ROSC. One pediatric neurologist analyzed the EEGs. EEGs were divided into having a score of 0 (normal/organized), 1 (slow and disorganized), 2 (discontinuous or burst suppression), and 3 (suppressed and featureless), and the criterion for suppression was $<10 \mu \mathrm{V}$ (Figure 1) (13). The presence of reactivity and electrographic seizures were also investigated.

In addition, we evaluated the gray matter to white matter attenuation ratio (GWR) on brain CT images after measuring the
Hounsfield unit (HU). Brain CT was performed using Sensation 16 or Definition Edge CT unit (Siemens, Erlangen, Germany), and one pediatric neurologist analyzed the images using imageviewing software (INFINITT PACS, Seoul, South Korea). With reference to previous studies reported by Metter (14), the HU values of the caudate nucleus $(\mathrm{CN})$, putamen $(\mathrm{PU})$, genu of the corpus callosum (CC), and posterior limb of the internal capsule (PIC) were obtained at the basal ganglia level of the brain CT. The GWR value was calculated by dividing the $\mathrm{HU}$ value measured in gray matter by the $\mathrm{HU}$ value in white matter $(\mathrm{GWR}=[\mathrm{CN}$ $+\mathrm{PU}] /[\mathrm{CC}+\mathrm{PIC}])$. On the brain CT images, $\mathrm{HU}$ values were obtained by dividing the total sum of the region of interest of $0.1-0.15 \mathrm{~cm}^{2}$ by area. Laboratory findings included ammonia, S-100, liver function tests, and blood gas analysis which were done in the emergency room. We selected the first results if there were multiple measurements including EEG, brain CT, and laboratory findings.

The primary outcome was assessed as a neurologic outcome at least 6 months after cardiac arrest. The neurologic outcome was evaluated according to the Pediatric Cerebral Performance Category (PCPC) as a score of 1 (normal), 2 (mild disability), 3 (moderate disability), 4 (severe disability), 5 (coma), and 6 (brain death) (15). PCPC score was determined based on the information in the medical record. Patients were divided into two groups: the good neurologic outcome group (PCPC 1-3) and the poor neurologic outcome group (PCPC 4-6).

This study was approved by the Institutional Review Board of Gachon University Gil Medical Center.

\section{Statistical Analysis}

Statistical analyses were computed using MedCalc Ver. 18.2.1 (MedCalc Software bvba, Ostend, Belgium). To compare the mean of two groups, the Student's $t$-test or Mann-Whitney $U$-test was used for normal distribution. The Chi-square test or Fisher's exact test was used for categorical variables. To evaluate the neurological prognostic performance of each test, sensitivity, specificity, and area under the curve (AUC) were calculated by receiver operating characteristic (ROC). Logistic regression analysis was used for the AUC of the combined model with two or more variables. $P<0.05$ were considered to be statistically significant.

\section{RESULTS}

\section{Patient Characteristics}

Total 203 out-of-hospital cardiac arrest patients aged 1 month to 18 years visited the hospital. Of 203 patients, 132 patients who were deceased on arrival, 42 patients who did not undergo an EEG within $72 \mathrm{~h}$, and eight patients who did not have a CT performed within $24 \mathrm{~h}$ were excluded. Ultimately, 21 patients (10.3\%) were included in the study.

According to the PCPC score, there were seven patients (33.3\%) with good neurological prognosis and 14 patients (66.7\%) with poor neurological prognosis. The median age for the good outcome group was 0.5 years (interquartile ranges [IQR] 0.3-12.0) and the median age of the poor outcome group was 1.2 years (IQR 0.3-9.1). There was no significant difference 
A

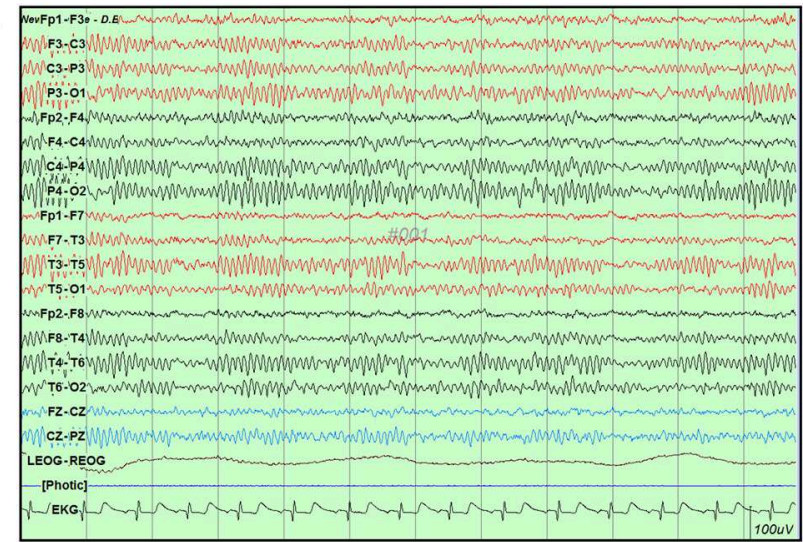

Score 0: normal/organized



Score 2: discontinuous or burst suppression
B

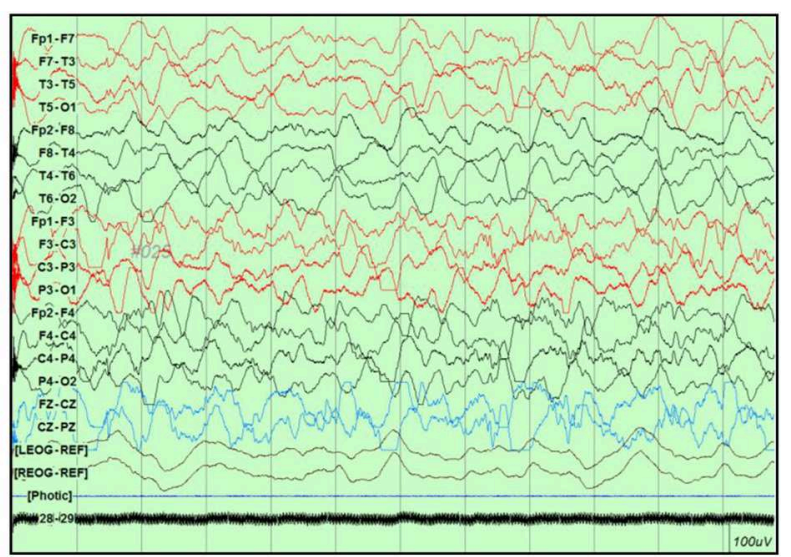

Score 1: slow and disorganized

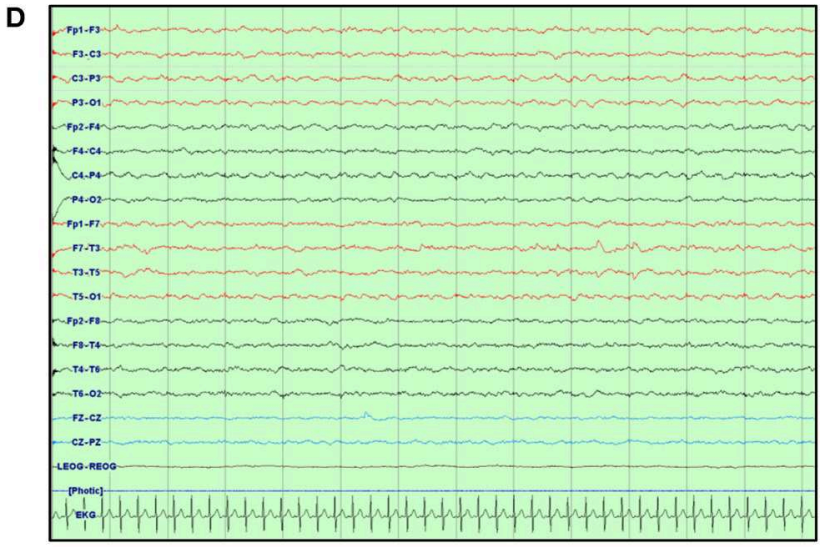

Score 3: suppressed and featureless

FIGURE 1 | EEG background scoring. (A) Score 0: normal/organized pattern (B) Score 1: slow and disorganized pattern (C) Score 2: discontinuous or burst suppression pattern (D) Score 3: suppressed and featureless pattern. EEG, electroencephalography.

in age between the two groups $(P=0.88)$. The mean time of cardiac arrest was $18.1 \pm 9.0 \mathrm{~min}$ in the poor outcome group and $11.4 \pm 9.3 \mathrm{~min}$ in the good outcome group, but there was no statistically significant difference $(P=0.13)$. The most common cause of cardiac arrest was asphyxia in both groups (good outcome group, 71.4\% and poor outcome group, $64.3 \%)$; there was no difference in underlying disease in both groups $(P=0.54)$. Therapeutic hypothermia was performed in 9 patients. There was no difference in time from ROSC to EEG evaluation between the two groups $(P=0.85)$. The rates of using muscle relaxant $(P=0.62)$, anticonvulsant $(P=0.35)$, and sedative drugs $(P=0.34)$ were similar between the groups during the EEGs (Table 1).

\section{Relationship Between EEG Findings and Neurological Outcome}

The ratio of the slow and disorganized pattern $(71.4 \%)$ in the EEG background was significantly higher in the good outcome group $(P=0.006)$, and the ratio of the suppressed and featureless pattern (92.9\%) was higher in the poor outcome group $(P=0.006)$. Patients in the good outcome group were more likely to have more reactivity to stimulation than those in the poor outcome group $(P=0.006)$. Notably, electrographic seizures were significantly more common in the good outcome group except if there was status epilepticus $(P=0.03)$ (Table 2).

\section{Prognostic Values of GWR on Brain CT and Laboratory Findings}

The mean value of GWR measured at the basal ganglia level on brain CT was $1.20 \pm 0.09$ in the good outcome group and significantly higher than $1.11 \pm 0.07$ in the poor outcome group $(P=0.03)$.

In the laboratory findings, the $\mathrm{pH}$ was significantly lower in the poor outcome group than in the good outcome group $(P=0.006)$ and the lactate level was significantly higher in the poor outcome group $(P=0.006)$. The serum ammonia level was markedly elevated in the poor outcome group (mean value: 422 $\mu \mathrm{g} / \mathrm{dL}$ [IQR 236-905]) than good outcome group (mean value: $83 \mu \mathrm{g} / \mathrm{dL}$ [IQR 68-268]) $(P=0.003)$ (Table 3). 
TABLE 1 | Clinical characteristics and neurologic outcomes.

\begin{tabular}{|c|c|c|c|}
\hline Characteristic & $\begin{array}{c}\text { Good } \\
\text { neurologic } \\
\text { outcome } \\
(n=7)\end{array}$ & $\begin{array}{c}\text { Poor } \\
\text { neurologic } \\
\text { outcome } \\
(n=14)\end{array}$ & $P$-value \\
\hline Age in years, median (IQR) & $0.5(0.3-12.0)$ & $1.2(0.3-9.1)$ & 0.88 \\
\hline Male sex, $n(\%)$ & $6(85.7)$ & $8(57.1)$ & 0.34 \\
\hline Arrest duration in minutes, mean $\pm \mathrm{SD}$ & $11.4 \pm 9.3$ & $18.1 \pm 9.0$ & 0.13 \\
\hline Arrest etiology, $n(\%)$ & & & 1.00 \\
\hline Asphyxia/Respiratory & $5(71.4)$ & $9(64.3)$ & 1.00 \\
\hline Cardiac & 0 & $1(7.1)$ & 1.00 \\
\hline Near drowning & 0 & $1(7.1)$ & 1.00 \\
\hline Others & $2(28.6)$ & $3(21.4)$ & 1.00 \\
\hline Preexisting conditions, $n(\%)$ & & & 0.54 \\
\hline None & $4(57.1)$ & $10(71.4)$ & 0.64 \\
\hline Neurologic & 0 & $2(14.3)$ & 0.53 \\
\hline Cardiac & $1(14.3)$ & $1(7.1)$ & 1.00 \\
\hline Other & $2(28.6)$ & $1(7.1)$ & 0.25 \\
\hline Initial cardiac rhythm, $n$ (\%) & & & 1.00 \\
\hline PEA & $1(14.3)$ & $2(14.3)$ & 1.00 \\
\hline V fib/ Tachycardia & 0 & $1(7.1)$ & 1.00 \\
\hline Asystole & $6(85.7)$ & 11 (78.6) & 1.00 \\
\hline Hypothermia treatment, $n(\%)$ & $3(42.9)$ & $6(42.9)$ & 1.00 \\
\hline ROSC to EEG onset, $n$ (\%) & & & 0.85 \\
\hline$<24 h$ & $3(42.9)$ & $7(50.0)$ & 1.00 \\
\hline Between 24 and $\leq 48 \mathrm{~h}$ & $3(42.9)$ & $4(28.6)$ & 0.64 \\
\hline Between 48 and $\leq 72 \mathrm{~h}$ & $1(14.3)$ & $3(21.4)$ & 1.00 \\
\hline \multicolumn{4}{|l|}{ Medication during EEG recording, $n(\%)$} \\
\hline Sedative drug & & & 0.34 \\
\hline Fentanyl & $1(14.3)$ & $1(7.1)$ & 1.00 \\
\hline Remifentanil & $1(14.3)$ & $3(21.4)$ & 1.00 \\
\hline Midazolam & $4(57.1)$ & $4(28.6)$ & 0.35 \\
\hline Muscle relaxant & & & 0.62 \\
\hline Vecuronium & 0 & $2(14.3)$ & 0.53 \\
\hline Rocuronium & $1(14.3)$ & $2(14.3)$ & 1.00 \\
\hline Antiepileptic drug & & & 0.35 \\
\hline Phenobarbital & $3(42.9)$ & $2(14.3)$ & 0.28 \\
\hline Phenytoin & $2(28.6)$ & $2(14.3)$ & 0.57 \\
\hline Valproic acid & $1(14.3)$ & $1(7.1)$ & 1.00 \\
\hline
\end{tabular}

IQR, interquartile ranges; $S D$, standard deviation; ROSC, return of spontaneous circulation; EEG, electroencephalography; PEA, pulseless electrical activity; $V$ fib, ventricular fibrillation.

\section{Combined Model of Single Predictors Using ROC Curve}

ROC analyses were performed to investigate the predictive performance of the single variable model and multimodal models of neurological prognosis (Table 4). The EEG evaluation showed that favorable EEG background categories (score 0,1) were associated with good outcome and the AUC was 0.821 (95\% confidence interval [CI] 0.595-0.952) $(P=0.001)$. Unfavorable EEG background categories (score 2,3) were associated with the poor outcome group $(P=0.001)$ and the AUC was 0.821 $(0.595-0.952)$, with a specificity of $92.9 \%$ and a positive predictive value of $83.4 \%$. Low GWR values on brain CTs predicted poor
TABLE 2 | EEG findings and neurologic outcomes.

\begin{tabular}{|c|c|c|c|}
\hline Finding & $\begin{array}{c}\text { Good } \\
\text { neurologic } \\
\text { outcome } \\
(n=7)\end{array}$ & $\begin{array}{c}\text { Poor } \\
\text { neurologic } \\
\text { outcome } \\
(n=14)\end{array}$ & $P$-value \\
\hline EEG background score, $n(\%)$ & & & 0.006 \\
\hline Score 0 (normal/organized) & 0 & 0 & NA \\
\hline Score 1 (slow and disorganized) & $5(71.4)$ & $1(7.1)$ & 0.006 \\
\hline $\begin{array}{l}\text { Score } 2 \text { (discontinuous or burst } \\
\text { suppression) }\end{array}$ & 0 & 0 & NA \\
\hline $\begin{array}{l}\text { Score } 3 \text { (suppressed and } \\
\text { featureless) }\end{array}$ & $2(28.6)$ & $13(92.9)$ & 0.006 \\
\hline Reactivity, $n$ (\%) & $5(71.4)$ & $1(7.1)$ & 0.006 \\
\hline Electrographic seizures, $n$ (\%) & & & 0.04 \\
\hline None & $4(57.1)$ & $12(85.7)$ & 0.28 \\
\hline Seizure & $3(42.9)$ & 0 & 0.03 \\
\hline Status epilepticus & 0 & $2(14.3)$ & 0.53 \\
\hline
\end{tabular}

EEG, electroencephalography; NA, not available.

TABLE 3 | Brain CT, laboratory findings, and neurologic outcomes.

\begin{tabular}{lccc}
\hline Characteristic & $\begin{array}{c}\text { Good } \\
\text { neurologic } \\
\text { outcome } \\
(\boldsymbol{n}=\mathbf{7})\end{array}$ & $\begin{array}{c}\text { Poor } \\
\text { neurologic } \\
\text { outcome } \\
(\boldsymbol{n}=\mathbf{1 4})\end{array}$ & P-value \\
\hline GWR in brain CT, mean \pm SD & $1.20 \pm 0.09$ & $1.11 \pm 0.07$ & 0.03 \\
Laboratory findings, median (IQR) & & & \\
S-100 $(\mu \mathrm{g} / \mathrm{L})(n=16)$ & $1.0(0.7-1.1)$ & $1.3(0.8-1.9)$ & 0.19 \\
AST $(\mathrm{U} / \mathrm{L})(n=21)$ & $70(42-245)$ & $238(128-337)$ & 0.08 \\
ALT $(\mathrm{U} / \mathrm{L})(n=21)$ & $36(19-218)$ & $143(58-201)$ & 0.13 \\
PH $(n=21)$ & $7.13(6.95-7.38)$ & $6.8(6.8-6.85)$ & 0.006 \\
Lactate $(\mathrm{mmol} / \mathrm{L})(n=21)$ & $4.4(3.5-13.6)$ & $15.0(11.8-15.0)$ & 0.006 \\
Ammonia $(\mu \mathrm{g} / \mathrm{dL})(n=21)$ & $83(68-268)$ & $422(236-905)$ & 0.003
\end{tabular}

$C T$, computed tomography; GWR, gray matter to white matter attenuation ratio; $S D$, standard deviation; IQR, interquartile ranges; AST, aspartate transaminase; ALT, alanine transaminase.

prognosis with an AUC of $0.776(0.543-0.926)(P=0.01)$, a cutoff value of 1.13 with a $71.4 \%$ specificity, and a cutoff value of 1.08 with $100 \%$ specificity. Hyperammonemia was predictive of poor prognosis $(P<0.001)$, with $71.4 \%$ specificity at a cutoff value of $147 \mu \mathrm{g} / \mathrm{dL}$ and $100 \%$ specificity at $334 \mu \mathrm{g} / \mathrm{dL}$; the AUC was $0.888(0.674-0.982)$.

For predicting poor neurologic outcome, the combination of unfavorable EEG background (score 2,3) and GWR had an AUC of 0.939 (0.742-0.997) and was higher than the AUC of $0.929(0.728-0.995)$ for the combination of unfavorable EEG background associated with ammonia. Finally, the combination of the three parameters of unfavorable EEG background, GWR, and ammonia had the greatest AUC (0.959 [0.772-0.999]), with $100 \%$ specificity and positive predictive value (Table 4; Figure 2). 
TABLE 4 | Predictive values for neurologic outcome.

\begin{tabular}{llcccccc}
\hline Variable & $\begin{array}{l}\text { Predicted } \\
\text { outcome }\end{array}$ & AUC & Sensitivity & Specificity & PPV & NPV & P-value \\
& & & & & & \\
\hline EEG background score 0, 1 & Good & $0.821(0.595-0.952)$ & $71.4(29.0-96.3)$ & $92.9(66.1-99.8)$ & $83.4(41.6-97.3)$ & $86.7(66.7-95.5)$ & 0.001 \\
EEG background score 2, 3 & Poor & $0.821(0.595-0.952)$ & $71.4(29.0-96.3)$ & $92.9(66.1-99.8)$ & $83.4(41.6-97.3)$ & $86.7(66.7-95.5)$ & 0.001 \\
Reactivity & Good & $0.821(0.595-0.952)$ & $71.4(29.0-96.3)$ & $92.9(66.1-99.8)$ & $83.4(41.6-97.3)$ & $86.7(66.7-95.5)$ & 0.001 \\
Electrographic seizures & Good & $0.714(0.478-0.887)$ & $42.9(9.9-81.6)$ & $100(76.8-100)$ & 100 & $77.8(64.9-87.0)$ & 0.03 \\
Brain CT GWR & Poor & $0.776(0.543-0.926)$ & $71.4(41.9-91.6)$ & $71.4(29.0-96.3)$ & $83.3(59.7-94.4)$ & $55.5(32.5-76.3)$ & 0.01 \\
Ammonia & Poor & $0.888(0.674-0.982)$ & $92.9(66.1-9.8)$ & $71.4(29.0-96.3)$ & $86.6(66.6-95.5)$ & $83.5(41.7-97.3)$ & $<0.001$ \\
EEG background 2, 3 + Ammonia & Poor & $0.929(0.728-0.995)$ & $92.9(66.1-99.8)$ & $85.7(42.1-99.6)$ & $92.8(67.8-98.8)$ & $85.8(47.1-97.6)$ & $<0.001$ \\
EEG background 2, 3 + Brain CT & Poor & $0.939(0.742-0.997)$ & $92.9(66.1-99.8)$ & $100(59.0-100)$ & 100 & $87.6(51.5-97.9)$ & $<0.001$ \\
GWR & & & & & & & \\
EEG background 2, 3 + Brain CT & Poor & $0.959(0.772-0.999)$ & $92.9(66.1-99.8)$ & $100(59.0-100)$ & 100 & $87.6(51.5-97.9)$ & $<0.001$ \\
GWR + Ammonia & & & & & & &
\end{tabular}

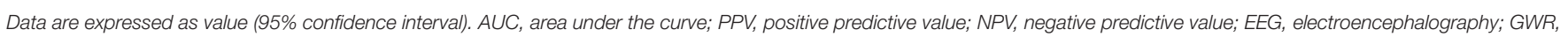
gray matter to white matter attenuation ratio.
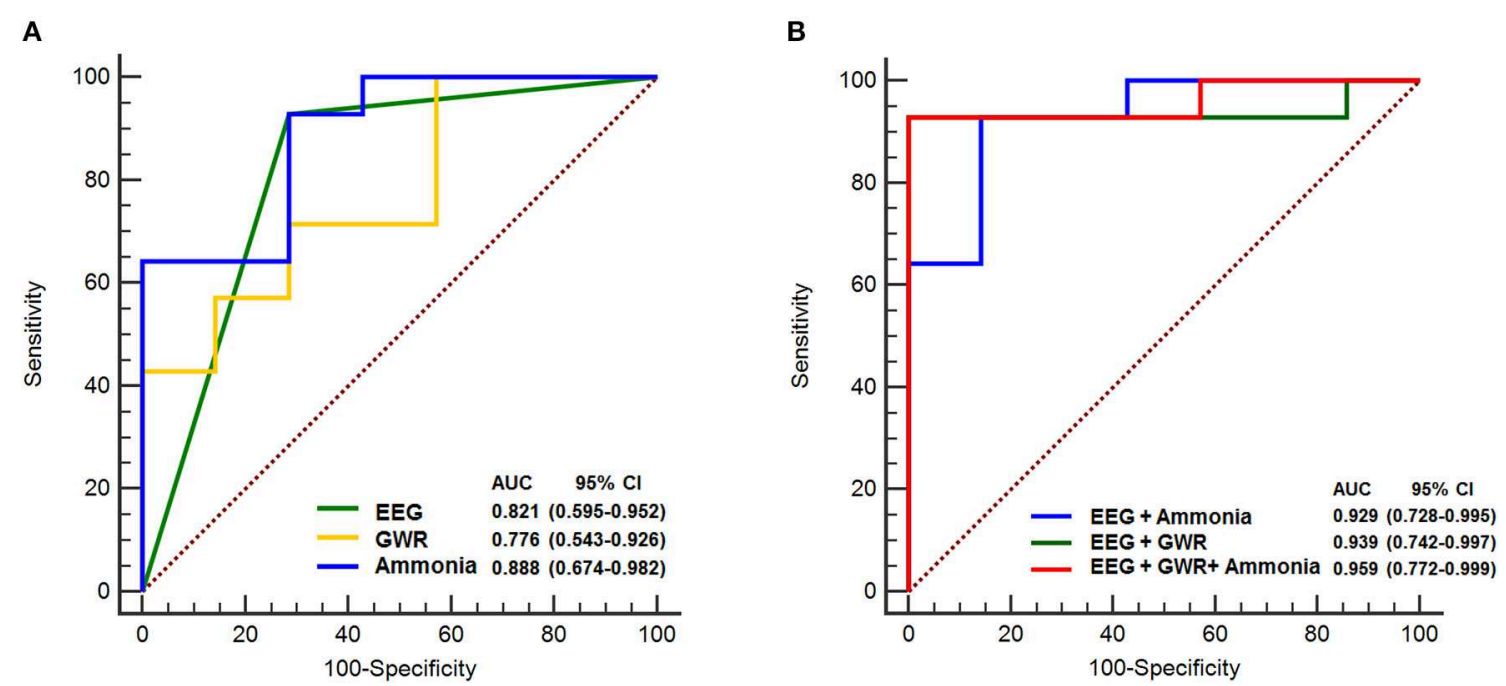

FIGURE 2 | ROC curves to predict poor neurologic outcome. (A) AUC for single variable, EEG background score 2, 3: 0.821, GWR: 0.776, Ammonia: 0.888 (B) AUC for combination of EEG and Ammonia: 0.929, EEG and GWR: 0.939, EEG and GWR and Ammonia: 0.959. ROC, receiver operating characteristic; AUC, area under curve; EEG, electroencephalography; GWR, gray matter to white matter attenuation ratio; Cl, confidence interval.

\section{DISCUSSION}

Brain damage in patients following cardiac arrest is affected not only by hypoxic-ischemic brain injuries that occur during cardiac arrest but also by reperfusion after resuscitation and recovery of blood circulation $(16,17)$. With this mechanism, multiple organs suffer from ischemic and reperfusion injury, which is called post-cardiac arrest syndrome (18). The survival rate of out-of-hospital cardiac arrest in pediatric patients is low, ranging from 3.3 to $15.8 \%$ (10). Even after survival, post-cardiac arrest syndrome can result in various sequelae. To determine the future treatment of patients who have recovered after cardiac arrest, many studies attempting to predict neurological prognosis have been performed. Neurological examinations are useful methods, but prognostication based on neurological examinations should be delayed in cases of hypothermic treatment (19). In contrast,
EEG is known to be largely unaffected by hypothermia (20), and laboratory findings such as ammonia, and brain CT are advantageous in that they can be performed quickly and easily when the patients arrive at the emergency room.

In previous studies on EEG and neurologic prognosis in pediatric patients after cardiac arrest, an unfavorable EEG or absence of the reactivity predicted poor prognosis (21), and favorable background predicted a good prognosis (7).

This study showed that patients had neurologically good outcomes when there was a slow and disorganized background pattern, and in cases of presence of a response to stimulation, whereas neurologically poor prognosis when there was a background of a suppressed and featureless pattern. The suppressed and featureless pattern of the EEG background reflects the severity of the brain damage and the loss of brain function. However, it should also be considered that 
sedative drugs administered during hypothermic treatment and ventilator application can affect EEG background. In this study, the frequency of using sedative drugs, muscle relaxants, and anticonvulsants was not different between the two prognosis groups. Topjian et al. reported that electrographic seizures were associated with good neurological prognosis (21). In this study, electrographic seizures were also associated with good neurological prognosis except for status epilepticus. Two patients with status epilepticus had a poor prognosis in spite of using active anticonvulsants and sedatives. Rundgren et al. also reported poor neurological prognosis in the presence of status epilepticus on EEG (22).

The advantage of brain CT is that it can be performed early when the patient arrives at the hospital and can help to identify the etiology. Torbey et al. proposed a method for quantitatively representing boundary loss by measuring gray and white HU values on brain CTs (23). Metter et al. reported that the reduction in GWR values obtained from the equation $(\mathrm{CN}$ $+\mathrm{PU}) /(\mathrm{CC}+\mathrm{PIC})$ at the basal ganglia level was associated with poor neurological prognosis (14). The mechanism by which the GWR value decreases in cardiac arrest is that the HU value of the gray matter decreases due to cytotoxic brain edema and neuronal necrosis when ischemic injury is present and the HU value increases due to the expansion effect of the vein entering into the white matter (24). Although studies have shown that patients with a GWR of $<1.18$ to $<1.22$ can predict the specificity of $100 \%$ of deaths in adults $(14,23,25)$, little has been done regarding the GWR values in children. Starling et al. reported that a GWR of $<1.14$ is predictive of death in pediatric patients, but the specificity was not $100 \%$ (8). In our study, the GWR cutoff value of 1.08 at the basal ganglia level showed $100 \%$ specificity for poor prognosis prediction and showed the highest specificity and sensitivity when the cutoff value was 1.13 . The lower cutoff value of GWR in children is due to the change in density of gray matter and white matter, probably associated with the normal myelination process $(26,27)$. In addition, attenuated CT protocol in pediatric patients might impact on the HU. However, we could not analyze the effect in detail.

Laboratory findings associated with the prognosis of cardiac arrest have been extensively studied in adult and pediatric patients, including $\mathrm{S}-100$ and $\mathrm{pH}$, but little has been studied regarding ammonia. Yanagawa et al. reported that hyperammonemia can predict poor prognosis with low blood $\mathrm{pH}$ in adult patients (9). This is because metabolic acidosis or respiratory acidosis leads to the release of ammonia from red blood cells. In this study, the median serum ammonia was 83 $\mu \mathrm{g} / \mathrm{dL}(68-268)$ in the good outcome group, and $422 \mu \mathrm{g} / \mathrm{dL}$

\section{REFERENCES}

1. Donoghue AJ, Nadkarni V, Berg RA, Osmond MH, Wells G, Nesbitt L, et al. Out-of-hospital pediatric cardiac arrest: an epidemiologic review and assessment of current knowledge. Ann
(236-905) in the poor outcome group. Cutoff value of $334 \mu \mathrm{g} / \mathrm{dL}$ showed specificity of $100 \%$.

Since the proposed prognostic predictor can improve the accuracy of the prognostic performance in the multimodal model, the prediction of the prognosis is suggested by combining various variables $(6,28-30)$. However, these multimodal models are limited to adult studies, and no studies have been reported on multimodal models of children. In this study, the AUC was calculated as $0.959(0.772-0.999)$, which had a $100 \%$ specificity and positive predictive value, by combining early EEG findings, GWR on brain CT, and serum ammonia.

The limitation of this study is that it was a retrospective study of a small number of patients in a single institution. Patients who had an EEG within $72 \mathrm{~h}$ were included even in patients who underwent hypothermic treatment, which can delay the timing of an EEG. Due to the small number of patients, it was impossible to analyze the prognosis according to the timing of the EEG.

In conclusion, the suppressed and featureless patterns of EEG in pediatric patients resuscitated from out-ofhospital cardiac arrest were significantly higher in the poor prognosis group, and reactivity to stimulation and electrographic seizures, except for status epilepticus, were higher in the good prognosis group. Additionally, low GWR values on brain $\mathrm{CT}$, lactic acidosis, and hyperammonemia were also significantly higher in the poor prognosis group. Unfavorable EEG background, low GWR on brain CT, and hyperammonemia are associated with poor neurological outcome in children resuscitated after an out-of-hospital cardiac arrest. In addition, the combined model of these prognosis predictors showed high specificity.

\section{DATA AVAILABILITY}

All datasets generated for this study are included in the manuscript and/or the supplementary files.

\section{ETHICS STATEMENT}

Institutional Review Board of Gachon University Gil Medical Center.

\section{AUTHOR CONTRIBUTIONS}

HK contributed conception and design of the study. DY and HK collected, analyzed, and interpreted the data, wrote and reviewed the manuscript. DY and ER performed the statistical analysis and reviewed the manuscript. All authors contributed to manuscript revision, read and approved the submitted version. 
Circulation. (2009) 119:1484-91. doi: 10.1161/CIRCULATIONAHA.108. 802678

3. Park CB, Shin SD, Suh GJ, Ahn KO, Cha WC, Song KJ, et al. Pediatric outof-hospital cardiac arrest in Korea: a nationwide population-based study. Resuscitation. (2010) 81:512-7. doi: 10.1016/j.resuscitation.2009.11.022

4. Moler FW, Donaldson AE, Meert K, Brilli RJ, Nadkarni V, Shaffner DH, et al. Multicenter cohort study of out-of-hospital pediatric cardiac arrest. Crit Care Med. (2011) 39:141-9. doi: 10.1097/CCM.0b013e3181fa3c17

5. Young KD, Gausche-Hill M, McClung CD, Lewis RJ. A prospective, population-based study of the epidemiology and outcome of out-ofhospital pediatric cardiopulmonary arrest. Pediatrics. (2004) 114:157-64. doi: $10.1542 /$ peds.114.1.157

6. Hofmeijer J, Beernink TM, Bosch FH, Beishuizen A, TjepkemaCloostermans MC, van Putten MJ. Early EEG contributes to multimodal outcome prediction of postanoxic coma. Neurology. (2015) 85:137-43. doi: 10.1212/WNL.0000000000001742

7. Ostendorf AP, Hartman ME, Friess SH. Early electroencephalographic findings correlate with neurologic outcome in children following cardiac arrest. Pediatr Crit Care Med. (2016) 17:667-76. doi: 10.1097/PCC.0000000000000791

8. Starling RM, Shekdar K, Licht D, Nadkarni VM, Berg RA, Topjian AA. Early head CT findings are associated with outcomes after pediatric out-of-hospital cardiac arrest. Pediatr Crit Care Med. (2015) 16:542-8. doi: 10.1097/PCC.0000000000000404

9. Yanagawa Y, Sakamoto T, Sato H. Relationship between laboratory findings and the outcome of cardiopulmonary arrest. Am J Emerg Med. (2009) 27:30812. doi: 10.1016/j.ajem.2008.03.001

10. de Caen AR, Berg MD, Chameides L, Gooden CK, Hickey RW, Scott HF, et al. Part 12: pediatric advanced life support: 2015 american heart association guidelines update for cardiopulmonary resuscitation and emergency cardiovascular care. Circulation. (2015) 132(18 Suppl. 2):S526-42. doi: $10.1161 /$ CIR. 0000000000000266

11. de Caen AR, Kleinman ME, Chameides L, Atkins DL, Berg RA, Berg MD, et al. Part 10: paediatric basic and advanced life support: 2010 international consensus on cardiopulmonary resuscitation and emergency cardiovascular care science with treatment recommendations. Resuscitation. (2010) 81(Suppl. 1):e213-59. doi: 10.1016/j.resuscitation.2010.08.028

12. ECC Committee, Subcommittees and Task Forces of the American Heart Association. American Heart Association guidelines for cardiopulmonary resuscitation and emergency cardiovascular care. Circulation. (2005) 112(24 Suppl):SIV1-203. doi: 10.1161/CIRCULATIONAHA.105.166550

13. Hirsch LJ, LaRoche SM, Gaspard N, Gerard E, Svoronos A, Herman ST, et al. American clinical neurophysiology society's standardized critical care EEG terminology: 2012 version. J Clin Neurophysiol. (2013) 30:1-27. doi: 10.1097/WNP.0b013e3182784729

14. Metter RB, Rittenberger JC, Guyette FX, Callaway CW. Association between a quantitative CT scan measure of brain edema and outcome after cardiac arrest. Resuscitation. (2011) 82:1180-5. doi: 10.1016/j.resuscitation.2011.04.001

15. Fiser DH, Long N, Roberson PK, Hefley G, Zolten K, Brodie-Fowler M. Relationship of pediatric overall performance category and pediatric cerebral performance category scores at pediatric intensive care unit discharge with outcome measures collected at hospital discharge and 1and 6-month follow-up assessments. Crit Care Med. (2000) 28:2616-20. doi: 10.1097/00003246-200007000-00072

16. Biagas K. Hypoxic-ischemic brain injury: advancements in the understanding of mechanisms and potential avenues for therapy. Curr Opin Pediatr. (1999) 11:223-8. doi: 10.1097/00008480-199906000-00009

17. Johnston MV, Trescher WH, Ishida A, Nakajima W. Neurobiology of hypoxicischemic injury in the developing brain. Pediatr Res. (2001) 49:735-41. doi: 10.1203/00006450-200106000-00003

18. Neumar RW, Nolan JP, Adrie C, Aibiki M, Berg RA, Bottiger BW, et al. Post-cardiac arrest syndrome: epidemiology, pathophysiology, treatment, and prognostication. A consensus statement from the International Liaison Committee on Resuscitation (American Heart Association, Australian and New Zealand Council on Resuscitation, European Resuscitation Council,
Heart and Stroke Foundation of Canada, InterAmerican Heart Foundation, Resuscitation Council of Asia, and the Resuscitation Council of Southern Africa); the American Heart Association Emergency Cardiovascular Care Committee; the Council on Cardiovascular Surgery and Anesthesia; the Council on Cardiopulmonary, Perioperative, and Critical Care; the Council on Clinical Cardiology; and the Stroke Council. Circulation. (2008) 118:245283. doi: 10.1161/CIRCULATIONAHA.108.190652

19. Dragancea I, Rundgren M, Englund E, Friberg H, Cronberg T. The influence of induced hypothermia and delayed prognostication on the mode of death after cardiac arrest. Resuscitation. (2013) 84:337-42. doi: 10.1016/j.resuscitation.2012.09.015

20. Stecker MM, Cheung AT, Pochettino A, Kent GP, Patterson T, Weiss SJ, et al. Deep hypothermic circulatory arrest: I. Effects of cooling on electroencephalogram and evoked potentials. Ann Thorac Surg. (2001) 71:14-21. doi: 10.1016/S0003-4975(00)01592-7

21. Topjian AA, Sanchez SM, Shults J, Berg RA, Dlugos DJ, Abend NS. Early electroencephalographic background features predict outcomes in children resuscitated from cardiac arrest. Pediatr Crit Care Med. (2016) 17:547-57. doi: 10.1097/PCC.0000000000000740

22. Rundgren M, Westhall E, Cronberg T, Rosen I, Friberg H. Continuous amplitude-integrated electroencephalogram predicts outcome in hypothermia-treated cardiac arrest patients. Crit Care Med. (2010) 38:1838-44. doi: 10.1097/CCM.0b013e3181eaale7

23. Torbey MT, Selim M, Knorr J, Bigelow C, Recht L. Quantitative analysis of the loss of distinction between gray and white matter in comatose patients after cardiac arrest. Stroke. (2000) 31:2163-7. doi: 10.1161/01.STR.31.9.2163

24. Sekhon MS, Ainslie PN, Griesdale DE. Clinical pathophysiology of hypoxic ischemic brain injury after cardiac arrest: a "two-hit" model. Crit Care. (2017) 21:90. doi: 10.1186/s13054-017-1670-9

25. Choi SP, Park HK, Park KN, Kim YM, Ahn KJ, Choi KH, et al. The density ratio of grey to white matter on computed tomography as an early predictor of vegetative state or death after cardiac arrest. Emerg Med J. (2008) 25:666-9. doi: $10.1136 /$ emj.2007.053306

26. Gennatas ED, Avants BB, Wolf DH, Satterthwaite TD, Ruparel K, Ciric R, et al. Age-related effects and sex differences in gray matter density, volume, mass, and cortical thickness from childhood to young adulthood. J Neurosci. (2017) 37:5065-73. doi: 10.1523/JNEUROSCI.355016.2017

27. Carmody DP, Dunn SM, Boddie-Willis AS, DeMarco JK, Lewis M. A quantitative measure of myelination development in infants, using MR images. Neuroradiology. (2004) 46:781-6. doi: 10.1007/s00234-004-1241-z

28. Youn CS, Callaway CW, Rittenberger JC, Post Cardiac Arrest S. Combination of initial neurologic examination, quantitative brain imaging and electroencephalography to predict outcome after cardiac arrest. Resuscitation. (2017) 110:120-5. doi: 10.1016/j.resuscitation.2016. 10.024

29. Lee BK, Jeung KW, Song KH, Jung YH, Choi WJ, Kim SH, et al. Prognostic values of gray matter to white matter ratios on early brain computed tomography in adult comatose patients after out-ofhospital cardiac arrest of cardiac etiology. Resuscitation. (2015) 96:46-52. doi: 10.1016/j.resuscitation.2015.07.027

30. Ryu JA, Chung CR, Cho YH, Sung K, Suh GY, Park TK, et al. The association of findings on brain computed tomography with neurologic outcomes following extracorporeal cardiopulmonary resuscitation. Crit Care. (2017) 21:15. doi: 10.1186/s13054-017-1604-6

Conflict of Interest Statement: The authors declare that the research was conducted in the absence of any commercial or financial relationships that could be construed as a potential conflict of interest.

Copyright (c) 2019 Yang, Ryoo and Kim. This is an open-access article distributed under the terms of the Creative Commons Attribution License (CC BY). The use, distribution or reproduction in other forums is permitted, provided the original author(s) and the copyright owner(s) are credited and that the original publication in this journal is cited, in accordance with accepted academic practice. No use, distribution or reproduction is permitted which does not comply with these terms. 